\title{
MÚSICA EN DIRECTO EN ESPAÑA: MALVIVIENDO ENTRE EXCESO DE NORMATIVAS
}

\section{Crismary Ospina Gallego}

Universitat Politécnica de València. Doctoranda

\section{Resumen}

Realizar música en vivo en locales pequeños es la realidad de los músicos independientes, es un escalón más que hay que recorrer en la profesión musical, además de ser el sustento de muchos artistas, ofrece un incremento de ingresos a los locales culturales que lo permiten realizar; Una simbiosis perfecta que requiere poca inversión por parte del establecimiento, poca logística por parte del artista y el público lo valora y disfruta muchísimo. En este artículo, se analizan el exceso de normativas, que hacen que ejercer la música independiente en España, sea una labor poco rentable, sacrificada y lleve al sector de la música en vivo a la precariedad laboral. Las leyes que regulan la música en vivo, están diseñadas para medianos y grandes eventos, olvidándose durante décadas de los locales de pequeño aforo que lo ofrecen, los cuales quedaron fuera del marco legal; Esta situación ha llevado a los locales culturales y artistas a arriesgarse a pagar grandes sumas en multas, o tener repercusiones legales para poder ofrecer cultura a sus clientes.

Palabras clave: MÚSICA EN VIVO; AFOROS; LOCAL CULTURAL; POLÍTICA MUSICAL; PRECARIEDAD LABORAL

\section{LIVE MUSIC OF SMALL LOCALS IN SPAIN: SURVIVING IN SPITE OF EXCESS OF REGULATIONS}

\section{Resume}

Performing live music in small venues is the reality of independent musicians, it is another step that must be taken in the musical profession, in addition to being the livelihood of many artists, it offers an increase in income to the cultural establishment allows performing; A perfect symbiosis that requires little investment from the hostelry, also little logistics from the artist and the public values it and enjoys it very much. In this article the laws that make the exercise of independent music in Spain an unprofitable and sacrificed task are analyzed. Guiding the live music sector to job insecurity. The laws that regulate live music are designed for medium and large events, forgetting for decades of small capacity concerts, which stayed outside the legal framework that has led cultural venues and artists to risk paying large sums in fines or have legal repercussions to offer culture to their clients.

Keywords: LIVE MUSIC, SMALL CONCERTS, CULTURAL VENUES, MUSICAL POLITICS, JOB INSECURITY

Ospina Gallego, Crismary. 2019. "Música en directo en España: Malviviendo entre exceso de normativas“. AusArt 7 (2): 91-102. D0I: 10.1387/ausart. 21142

\section{AUSART}




\section{METODOLOGÍA}

El objetivo de la investigación, consiste en encontrar las principales causales de la precariedad laboral en los conciertos de música en directo no masiva. Inicialmente se pensó que la parte económica era la causal más importante, así que se analizaron variables que afectaran directamente los ingresos de los músicos en estas presentaciones, como: Oferta y demanda, consumo cultural de España, el IVA, la paulatina desinversión publica en cultura y Ley de espectáculos públicos

No todos los factores antes mencionados tuvieron un impacto en el objeto de estudio. Los 3 primeros son variables que cada vez favorecen menos a la música, pero según las investigaciones y datos obtenidos, los conciertos de pequeño aforo no se vieron modificados significativamente por ellos; Por esta razón los descartamos.

El factor más significativo fue el de la ley de espectáculos públicos, ya que si la ley se modifica se afecta directamente la sobrevivencia de esta actividad en una comunidad autónoma completa, afectando el gremio musical y los locales culturales de toda una región.

Por esta razón se estudió más a fondo la ley de espectáculos públicos en España.

- Se averiguaron los antecedentes de las leyes.

- Se estudiaron las leyes de espectáculos públicos de las 19 comunidades autónomas.

- Se buscaron movimientos de protesta en contra de esta ley en prensa local.

- Se contrastaron las consecuencias para los músicos con situaciones similares en otros países.

Cada comunidad autónoma tiene sus propias leyes y parámetros para legalizar la música en vivo en locales de pequeño aforo, así que no se pudo hacer un formato general de preguntas para todas las regiones, por esta razón se recogió la mayor cantidad de información posible sobre el tema de cada comunidad. Posteriormente se trató de unificar conceptos para generar gráficos y sacar conclusiones con los datos recaudados. 
La información más completa que se recaudo fue la siguiente:

- Requisitos para obtener la licencia.

- ¿Se puede tocar en locales de pequeño aforo sin licencia?

- ¿Permite ingreso de menores de edad a estos eventos?

- ¿Los afectados hicieron huelga para modificar la norma? ¿fueron escuchados?

\section{LEY DE ESPECTÁCULOS PÚBLICOS}

Los conciertos de pequeño aforo se rigen por la ley de espectáculos públicos, o en algunos casos la ley del turismo de cada comunidad autónoma. La normativa es diferente para cada localidad de España, cualquier modificación en ella respecto a la música en vivo afecta directamente los conciertos de pequeño aforo'.

\section{Antecedentes}

El reglamento de Espectáculos Públicos aprobado en el año 1935, trató de homogeneizar las disposiciones que se encontraban en un conjunto dispar de normas. Este contemplaba el bar-cantante y el café-cantante como bares donde se podía realizar música en vivo de pequeño formato. Se precisaba la autorización del director general de seguridad en Madrid o alcaldes en las localidades y se concedía o denegaba dependiendo de que el lugar cumpliera con normas de moral, decoro o tranquilidad pública; Estaban prohibidas las canciones obscenas, bailes lascivos y cualquier otro acto contrario a la moral. También el espectáculo no podrá terminar después de las 12 de la noche (Reglamento General de Policía de Espectáculos Públicos y Actividades Recreativas, cap. VI, art. 58,60)

Los festivales de música aparecen en los años 50 , eran básicamente una competencia de cantantes y tuvieron mucho éxito, 20 años más tarde empezaron los festivales de música al aire libre; En 1975 después de la muerte de franco empezó la era de los grandes festivales (Delgado 2019). 
Pronto el contexto social del que era objeto la normativa empezó a cambiar, creando una serie de necesidades y exigencias que en algunas ocasiones eran contradictorias. El incremento del sector ocio y tiempo libre para satisfacer las demandas de la población y como generador de empleo e inversiones, tiene que conciliarse con otros derechos e intereses de la ciudadanía como son: La seguridad de los espectáculos, la protección de la infancia, del medio ambiente y el descanso de los vecinos ${ }^{2}$.

Para el año 1982 se empiezan a realizar actualizaciones de esta ley en las comunidades autónomas, interesadas en regular y organizar los medianos y grandes y eventos públicos, empezando con aforos de 250 personas en adelante. Dejando en un limbo jurídico a los pequeños locales culturales; aunque la actualización de 1982 no es muy estricta en términos de seguridad, las actualizaciones más modernas si lo son (Real Decreto 2816/1982).

Para realizar un concierto de entre 250 y 1500 personas se deben tener en cuenta ciertos aspectos logísticos para preservar la seguridad y comodidad de los asistentes. Estructuras como: Control de acceso, control de flujos, salida de emergencia, escenario, camerinos, guardarropa, personal de seguridad, suficientes baños, ventilación, personal de emergencias, seguro de accidentes, insonorización del lugar (Peñalvert Bonet 2014).

Para corroborar que estas condiciones se cumplan a la hora de ofrecer los conciertos, se utiliza la licencia de espectáculos, que tiene como por objeto: comprobar que la construcción o la reforma y las instalaciones se ajustan íntegramente a las previsiones del proyecto, previamente aprobado por el Ayuntamiento.

Las regulaciones les exigen a locales de 75 a 150 personas de aforo las mismas condiciones que una sala de conciertos de 250 asistentes, como es actualmente el caso de País Vasco, Navarra, Galicia, La Rioja, Asturias.

La inversión requerida para obtener esta licencia, varía dependiendo de las exigencias de cada comunidad autónoma, así como el estado del local. Pueda que las obras sean tan costosas que no sea rentable el negocio, o bien, no sea posible llevarlo a cabo ${ }^{3}$.

A pesar de los locales culturales de pequeño aforo no se les ha otorgado licencia, el público sigue interesado en este tipo de eventos, Los hosteleros y 
músicos empiezan a ofrecer estos eventos fuera del marco legal, siendo conscientes de las consecuencias legales y las multas que esto acarrea ${ }^{4}$.

Después del incidente del Arena de Madrid, donde en un concierto de música electrónica se supero el aforo permitido, causando la muerte a 5 jóvenes por avalancha. Madrid, Aragón y otras comunidades autónomas empezaron a regular con mayor severidad la ley de espectáculos públicos y actividades recreativas, empezaron a exigir mayores medidas de seguridad a los locales que ofrecen música en vivo (Mateo \& Barroso 2018).

Los hosteleros al no poder cumplir con estos requisitos, cierran la posibilidad de hacer pequeños conciertos en sus locales. No sin antes, realizar huelgas con colectivos de artistas, vecinos, locales culturales y hacerse sentir acerca de la injusta persecución que los oprime (Lamadrid 2017).

Las huelgas consiguen mejorar las condiciones en algunas comunidades autónomas, las cuales regulan sabiamente, para que los pequeños hosteleros que realizan actividades culturales periódicamente puedan seguirlo haciendo sin restricciones legales, respetando la seguridad de los asistentes y el descanso de los vecinos, como es el caso de Andalucía, Cantabria, Castilla León, Cataluña, La Rioja, Valencia (Cruz 2016).

Otras comunidades establecen permisos que se deben solicitar entre 20 y 15 días hábiles previos, adjuntando un conjunto de requisitos que varían desde croquis del lugar, seguro de responsabilidad civil, hasta fianza para daños públicos que ocasione el evento. Infortunadamente, otorgan el permiso entre 2 y 5 días antes del evento, lo cual es tarde para realizar la publicidad del espectáculo y confirmar a los artistas; Además para cumplir los requisitos, en algunas comunidades se debe incurrir en gastos adicionales importantes para obtenerlo, sin contar que los locales que realizan estas actividades suelen hacerlo al menos una vez por semana. Esta situación la sufre Castilla la Mancha, Extremadura, Islas Baleares, Navarra, País Vasco.

Otras comunidades autónomas prohibieron este tipo de actividades culturales sin la debida licencia estas son: Aragón, Asturias, Ceuta y Melilla, Galicia, Islas Canarias, Madrid y Murcia (Gonzalez 2018). 


\section{CONSECUENCiAs PARA los músicos}

En argentina, tras el incendio en el establecimiento República de Cromañón, durante un concierto de Rock murieron 194 personas y 725 más resultaron heridas (Vera 2014). Durante el evento se triplico el aforo permitido y no había medidas de seguridad eficaces, ocasionando la tragedia. Con el acontecimiento, se decidió cambiar la normativa, exigiendo medidas de seguridad más estrictas para los locales (Corti 2010).

Las consecuencias para Argentina en el panorama de la música en vivo de pequeño aforo implico que la legislación, empezó a exigir unas regulaciones que solo podían ser asumidas por locales que tuvieran a la mano la inversión necesaria para modificar su estructura física a las nuevas exigencias de la norma como está ocurriendo en España.

Los lugares donde se permite música en vivo después de la tragedia son un número mucho más reducido, aumentando el nivel de su convocatoria. Para poder tocar allí se requiere una gran trayectoria y gran currículum, de esta manera un músico independiente, debe competir contra muchas otras bandas o proyectos consolidados para tocar en los pocos lugares que tienen licencia. Se aumenta la oferta de música en vivo, pero no hay demanda de lugares donde tocar; En estos casos los hosteleros prefieren contratar a bandas reconocidas, porque estas les aseguran una cantidad de público mayor (Corti 2010).

Las consecuencias mencionadas anteriormente las viven actualmente algunas comunidades autónomas de España tras la excesiva regulación de la ley de espectáculos, situación que se evidencia en el estudio cartografías musicales de Madrid, donde se muestra que de 55 lugares que solían hacen música en vivo están activos solo 25 tras entrar en vigor la norma (Josep 2017).

Al haber mucha oferta de músicos y poca demanda de lugares donde tocar, es inminente la caída de precios, también se inicia una guerra por tocar en lugares. Los grupos independientes empiezan a conseguir mánager y prensa lo cual aumenta sus probabilidades de acceder a estos conciertos, pero ahora pagan menos, se debe dividir el dinero a mas partes y para poner más presión aún, la responsabilidad de llevar publico recae en el grupo (Andrews 2016).

Las salas medianas de entre 250 y 500 espectadores suelen cobrar entrada con boletería, los artistas deben pagar alquiler del escenario y pagar el per- 
sonal de luz y sonido; Otra forma tocar en salas es asegurando una mínima cantidad de tickets para confirmar el evento, para ello el grupo debe comprar por adelantado los tickets exigidos y luego regalarlos, por lo cual el evento ya no sale rentable para los músicos, pero en cualquiera de los casos, el grupo se reconforta teniendo circulación (Viana \& Villuendas 2019).

"Se genero una limitación en la circulación de la música independiente, reacomodando el mercado, tendientes a la concentración, donde se afianzaron los productores masivos de la industria discográfica, solo producto rentable y seguro se convirtieron en los únicos habilitados para difundir su obra arriba de un escenario".

(Corti 2010).

\section{RESULTADOS DE LA INVESTIGACIÓN}

La siguiente información surge de un estudio realizado por la redactora del artículo, se analizaron las leyes de espectáculos públicos de las 19 comunidades autónomas, verificando datos de las regulaciones específicas que afectan directamente música en vivo de pequeño formato y se encontró la siguiente información.

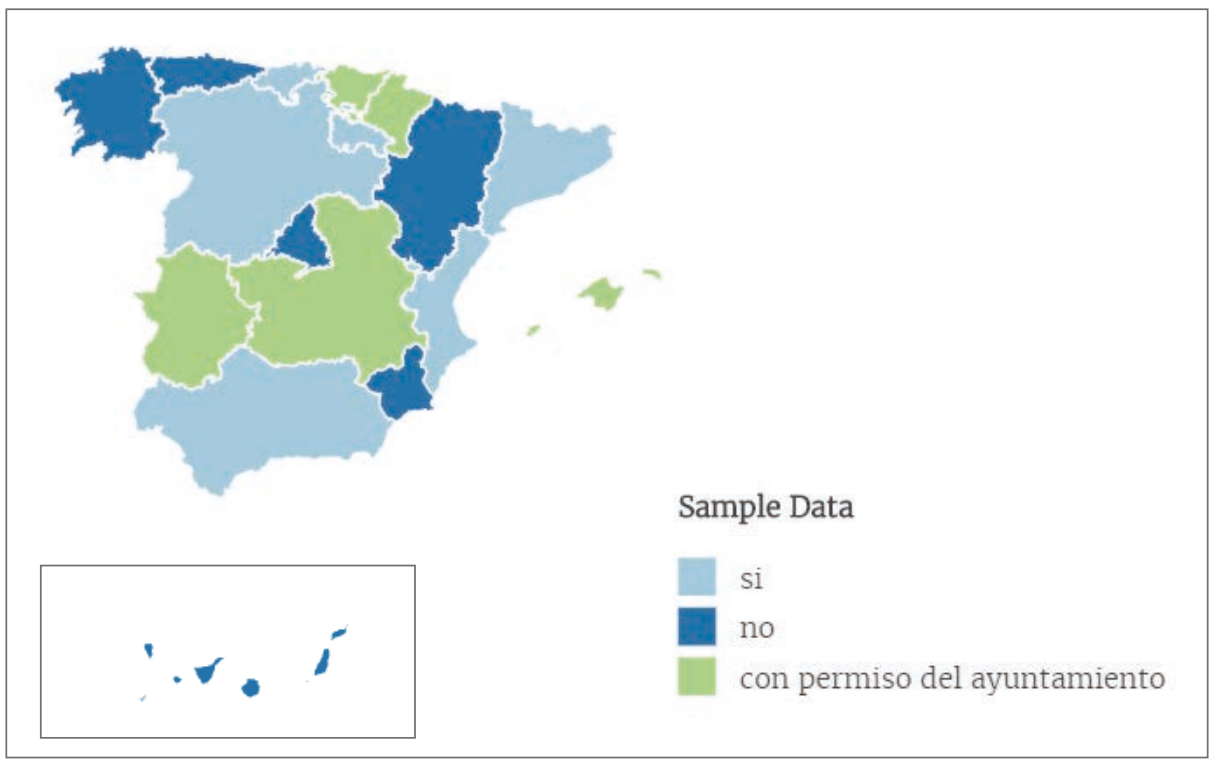


A continuación se muestra un mapa de las comunidades autónomas de España que permiten o no música en vivo en locales de pequeño aforo sin licencia.



\section{LAS MEJORES CIUDADES PARA REALIZAR CONCIERTOS DE PEQUEÑO FORMATO EN HOSTELERÍA SON:}

Andalucía: Esta legislación fue que fue redactada por hosteleros, vecinos y músicos, los cuales pudieron llegar a acuerdos respetando las necesidades de cada uno. En esta ciudad no se registró huelga por parte de colectivos, ya que los implicados fueron escuchados a tiempo.

Cataluña: Parte del éxito de esta legislación, fue un estudio que realizo el ayuntamiento acerca de la música en vivo en la ciudad, en la cual, se identifico que la música en directo de pequeño aforo se realizaban con más frecuencia y en mayor cantidad que los conciertos en salas medianas, por la facilidad de la logística. También se identifico que el factor de amplificación era un factor determinante a la hora de la necesidad de insonorización de un local, ya que si el concierto se realiza en formato acústico no rompe el descanso de los vecinos y no es necesario incurrir en el gasto de insonorizar el local; En esta ciudad tampoco hay notas de prensa que evidencien huelgas por parte de músicos u hosteleros. 
Valencia: se consiguió mejorar la legislación porque se formo un colectivo de bares culturales, quienes realizaron recolección de firmas, así como plantones con artistas en el ayuntamiento, se involucraron a algunos políticos y personas que pudieran comunicar el mensaje dentro de los círculos que tienen el poder para cambiar la norma, y sus peticiones fueron escuchadas.

\section{DE LAS CIUdAdES MÁS REPRESIVAS CON LA MÚSICA EN ViVO DE PEQUEÑO FORMATO SE ENCUENTRAN:}

País Vasco: Limita a 12 las actuaciones a realizar en el año para los locales que no tengan licencia debiendo solicitar permiso previo, no pueden realizarse más de 2 eventos en el mismo mes. La ley contempla que los locales para realizar actuaciones en directo necesitan camerinos individuales de mujeres y de hombres, así como salidas de emergencia, guardarropa, y una persona encargada de la vigilancia, lo cual es inviable de modificar por cuestión de inversión y espacios para un local pequeño; Los colectivos se han manifestado pero no han sido escuchados.

Madrid: En la capital española los músicos y hosteleros han protestado ante esta legislación pero sus peticiones han sido ignoradas. Solían existir 55 lugares de música en directo pero actualmente solo quedan 25 .

Murcia: En Murcia a los colectivos les parece injusto que en la calle y en los bares puedan poner música reproducida, pero música en directo esta sancionada aunque ocupe los mismos decibeles. Inclusive hay bares que tienen insonorización pero su licencia es de bar y no se les permite contratar siquiera ni un mago; En el 2018 han sancionado 10 bares y 20 más han recibido una carta de advertencia por esta causa.

\section{CONCLUSIONES}

La música en directo está intentando sobrevivir a pesar del exceso de regulaciones que imponen. Lo positivo de la situación es que el sector musical y hostelero está uniéndose y pronunciándose, haciendo huelgas y protestando contra la persecución al trabajo honesto; Es importante seguir realizando manifestaciones, para que como en Cataluña y Andalucía, se consiga un com- 
plemento entre la ley y el descanso de los vecinos y se logre eliminar obstáculos a actividades económicas creativas, que merecen un hueco en el mercado.

La ley de espectáculos trae exigencias imposibles de cumplir para pequeños locales que quieran adquirir la licencia de espectáculos. En varias comunidades autónomas es una ley hecha a espaldas del sector implicado, aumentando la precariedad laboral; Se ha obligado a los locales culturales a cerrar las puertas al arte perdiendo oportunidades de trabajo para artistas y reduciendo ingresos a los hosteleros, o a realizar las actuaciones al margen de la ley, arriesgándose a pagar grandes sumas de dinero en caso de ser inspeccionados.

La reducción de locales para actuar ha llevado a los músicos a irregularidad en sus obligaciones legales, los ha obligado a la polivalencia, a dar clases, trabajar de medio tiempo en otra industria, o a exiliarse para poder vivir de su profesión, lo cual empobrece el desarrollo musical de las regiones.

Las Subida del $8 \%$ al $21 \%$ en el año 2012 al impuesto IVA cultural tuvo efectos nefatos para el sector musical, ya que los productores debieron subir los precios de los eventos para poder seguir en circulación, lo cual repercutió en que el publico paulatinamente bajo la asistencia a los eventos culturales de mediano aforo.

Este hecho favoreció a los conciertos no masivos, ya que al aumentar los precios de las entradas a conciertos de aforo mediano, el público paulatinamente dejo de asistir a eventos culturales, volcando sus actividades culturales a unas más económicas. Los conciertos de pequeño aforo muchos de ellos no cobran boletería porque los grupos que actúan ahí son independientes en fases iniciales de su carrera musical y en caso de que se pague boletería será a un precio simbólico.

La desinversión publica en cultura no afecto a este tipo de actividad porque no se beneficia por este tipo de ayudas, se lucra con los pagos de los dueños del local cultural o la venta de entradas.

11 comunidades autónomas permiten la entrada de menores de edad acompañados de sus padres o tutores, algunas comunidades admiten mayores de 16 años solos con algunas restricciones, es un avance importante ya que abre la posibilidad de que las familias puedan asistir a los conciertos, y los adolescentes pueden realizar actividades de ocio saludable. 


\section{Glosario}

Música en vivo no masiva: Interpretación de música por un solista o agrupación, donde el público no supera las 150 personas.

Locales culturales: Espacio donde se lleva a cabo una programación estable, vinculada a la música en directo, artes escénicas o manifestaciones de arte y cultura popular.

Licencia para espectáculos públicos Tiene como por objeto, comprobar que la construcción o la reforma y las instalaciones, se ajustan íntegramente a las previsiones del proyecto previamente aprobado por el Ayuntamiento.

Pequeño aforo: Capacidad de un local comercial, 150 personas máximo.

Música independiente: Música que llega al público solo con los medios del artista, sin una discográfica que lo apoye. En este artículo se hace referencia a proyectos musicales en sus etapas iniciales.

\section{Referencias bibliográficas}

Andrews Alex. 2016. "Guía básica para programar conciertos: Dirigirse a una sala". CDBaby, 22 junio. https://musicodiy.com/guia-basica-para-programar-conciertos-dirigirse-a-una-sala/

Corti, Berenice. 2010. "Redefiniciones culturales en la Buenos Aires post Cromañón: El debate sobre el vivo de la música independiente". Tesis de maestría Univ. Buenos Aires

Cruz, Nando. 2016. "Todos los bares de Barcelona podrán ofrecer música en directo". El Periódico. 14 marzo

Delgado, Andrea. 2019. "Ya llegan los festivales de música: Y con ellos toda su historia". Menzig, 6 mayo https://www.menzig.es/a/festivales-historia-mas-importantes/

González, José Alberto. 2018. "El ayuntamiento de Cartagena pone coto a los bares que organizan conciertos sin tener autorización". La Verdad 13 nov. https://www.laverdad.es/ murcia/cartagena/ayuntamiento-pone-coto-20181113010227-ntvo.html

Lamadrid, Paloma. 2017. "Sin música en directo por un limbo legal". El Comercio 17 abril. https://www.elcomercio.es/gijon/201704/17/musica-directo-limbo-legal-20170417010727-v. $\mathrm{html}$

Mateo Ruiz-Gálvez, Juan José \& F. Javier Barroso Simón. 2018. "EI PSOE reclama que el Gobierno regule por ley la seguridad en macrofiestas y festivales de música”. El País 3 nov. https://elpais.com/ccaa/2018/11/01/madrid/1541097921_138398.html

Pedro Carañana, Josep. 2017. "Cartografías musicales de Madrid: Ciudad, música popular y nuevas tecnologías digitales" CIC Cuadernos de Información y Comunicación 22:169-85

Peñalvert Bonet, Juan. 2014. "Guías de buenas prácticas para macroespectáculos". Es Pont d'Inca: Instituto de Seguridad Pública de las Illes Balears (ISPIB)

Vera Rojas, Yumber. 2014. "El concierto más trágico del mundo". El País, 20 dic. https://elpais. com/internacional/2014/12/29/actualidad/1419888729_364738.html

Viana Silva, Israel \& Javier Villuendas Pérez. 2019. "Músicos contra salas: la batalla 'imposible' por vivir de los conciertos". ABC, 23 enero. https://www.abc.es/cultura/musica/abci-musicos-contra-salas-batalla-imposible-para-vivir-conciertos-201809290147_noticia.html 


\section{Legislación}

Orden de 3 de mayo de 1935 por el que se aprueba el Reglamento de Espectáculos Públicos (Gaceta del 5 de mayo de 1935, corregida por otra Gaceta de 8 de mayo).

Real Decreto 2816/1982, de 27 de agosto, por el que se aprueba el Reglamento General de Policía de Espectáculos Públicos y Actividades Recreativas (BOE núm. 267, de 6 de noviembre).

\section{Notas}

${ }^{1}$ Legislación básica de espectáculos en las comunidades autónomas. Web Ministerio del Interior [Servicios al ciudadano $\rightarrow$ Trámites y gestiones $\rightarrow$ Espectáculos http://www.interior. gob.es/web/servicios-al-ciudadano/espectaculos/espectaculos/legislacion-basica-de-comunidades-autonomas]

2 "Establecimientos, espectáculos y actividades recreativas: Competencias municipales y actuación policial". Seguridadpublica.es, Temarios opositores. 1 oct. 2010 https://www. seguridadpublica.es/2010/10/establecimientos-espectaculos-y-actividades-recreativas-competencias-municipales-y-actuacion-policial/

3 "Música en vivo en bares y restaurantes ¿vale la pena?". Solocamarasfrigorificas.com, 15 enero 2018 https://www.solocamarasfrigorificas.com/blog-articulos/19-consejos/34-musica-en-vivo-en-bares-y-restaurantes

4 "La Policía denuncia a 4 bares por tener música en directo sin licencia". El Día de Valladolid, 1 marzo 2019. https://www.eldiadevalladolid.com/noticia/Z59118585-B4A7-7361B8752449A2A936EB/20130301/policia/denuncia/4/bares/tener/musica/directo/licencia 